\title{
THE DUAL EFFECTS OF INTELLECTUAL PROPERTY REGULATIONS: WITHIN- AND BETWEEN- PATENT COMPETITION \\ IN THE US PHARMACEUTICALS INDUSTRY
}

\author{
Frank R. Lichtenberg \\ Tomas J. Philipson \\ Working Paper 9303 \\ http://www.nber.org/papers/w9303 \\ NATIONAL BUREAU OF ECONOMIC RESEARCH \\ 1050 Massachusetts Avenue \\ Cambridge, MA 02138 \\ October 2002
}

\begin{abstract}
We are thankful for comments on the paper by numerous seminar audiences and in particular by Stephen Propper and Ernie Berndt. Both authors are thankful for financial support from Pfizer Inc, Astra -Zeneca, and Merck \& Co., and Philipson from The George Stigler center for The Study of The Economy and The State. The views expressed herein are those of the authors and not necessarily those of the National Bureau of Economic Research.

(C) 2002 by Frank R. Lichtenberg and Tomas J. Philipson. All rights reserved. Short sections of text, not to exceed two paragraphs, may be quoted without explicit permission provided that full credit, including (C) notice, is given to the source.
\end{abstract}


The Dual Effects of Intellectual Property Regulations:

Within- and Between- Patent Competition in the US Pharmaceuticals Industry

Frank R. Lichtenberg and Tomas J. Philipson

NBER Working Paper No. 9303

October 2002

JEL No. I1, L1, K2

\section{$\underline{\text { ABSTRACT }}$}

A patent only protects an innovator from others producing the same product, but it does not protect him from others producing better products under new patents. Therefore, one may divide up the source of competition facing an innovator into within-patent competition, which results from production of the same product, and betweenpatent competition, which results from production of products on other patents. Previous theoretical and empirical micro -based analyses have emphasized the effects of intellectual property regulations on within -patent competition by showing how protecting innovative returns from imitators raises $R \& D$ incentives. However, between-patent competition affects innovative returns, particularly through creative destruction in the many high-tech industries that seem central to overall economic progress. This suggests that a fuller understanding of IP-regulations take into account its effects on between-patent competition. We find that the total effects of intellectual property regulations depend heavily on whether these unexplored effects are present. We attempt to estimate the relative magnitudes of the two sources of competition in limiting innovative returns in the U.S. pharmaceuticals market. In this market within -patent competition from so-called generic producers has been analyzed relatively more compared to competition between-patents through so called therapeutic competition. We estimate that between-patent competition, most of which occurs while a drug is under patent, costs the innovator at least as much as within-patent competition, which cannot occur until a drug is off patent. The reduction in the present discounted value of the innovator's return from between-patent competition appears to be at least as large as the reduction from competition within -patents, and may be much larger.

Frank R. Lichtenberg

Graduate School of Business

Columbia University

3022 Boradway, 726 Uris Hall

New York, NY 10027

and NBER

frank.lichtenberg@columbia.edu
Tomas J. Philipson

Department of Economics

University of Chicago

1155 East $60^{\text {th }}$ Street

Chicago, IL 60637

and NBER

t-philipson@uchicago.edu 


\section{INTRODUCTION}

Economists have long appreciated the importance of R\&D and technological change for economic progress and there is a large literature analyzing the sources and consequences of technological change. Consequently, economists have also been interested in understanding the effects and desirability of public interventions affecting the amount and speed of technological change. Such policies include, for example, direct R\&D tax-incentives, nonprofit tax exemptions for research institutions, public financing of R\&D activity, as well as many other instruments attempting to stimulate various forms of research and innovative activity.

Perhaps the most important and direct policies affecting R\&D are intellectual property regulations, especially patent, copyright, and trademark policy. There is a substantial body of theoretical work examining the effects of these intellectual property regulations on the amount of innovation they induce. Traditional theoretical analyses generally assesses the impact of intellectual property (IP) regulations through their effect on protecting innovative returns from potential imitators by focusing on how those regulations affect the behavior of subsequent imitators producing the same product as the innovator ${ }^{2}$.

However, the loss of innovative returns due to such within-patent competition from imitators, for example through patent expiration, is of course only one way in which innovative returns may be destroyed. The other is through between-patent competition from new patents being developed by competitors. A patent only protects an innovator from others producing the same product, but it does not protect him from others producing better products under new patents. For example, in the pharmaceutical industry, within -patent competition after patent expiration is from so called generic manufacturers, and between-patent competition through new patents is from so called brandname manufacturers engaging in therapeutic competition within diseases and drug classes. Between-patent competition may be as important a limit on innovative returns as within-patent competition. This is particularly true in high-tech fields, which may be important to aggregate productivity growth, such as the telecommunications, biotechnology, and pharmaceutical industries. In these industries, the demand for a given innovation is often destroyed by entry of new, superior products long before patent expiration. In addition, within-patent competition

\footnotetext{
${ }^{2}$ Reducing imitation is the implicit value of IP regulations in microeconomic analysis of, for example, Nordhause (1969), Wright (1983), Judd (1985), Gilbert and Shapiro (1990), Klemperer (1990), Horstman et al . (1993), Gallini (1992), Green et al (1995), and Scotchmer (1996). Following Schumpeter, there also is a substantial macro -economic literature on the growth effects of creative destruction, see, for example, Aghion and Howitt (1992). Although related, this literature does not consider the effects of IP regulations on firm-level R\&D incentives as stressed here.
} 
occurs many years in the future, thereby being less important for the present value of innovative returns, and also occurs after the between-patent competition has had time to run its course. Therefore, extensive "creative destruction" through between-patent competition leaves less to be subsequently destroyed by "uncreative" withinpatent competition.

To gain a more complete understanding of the effects of IP regulations on innovative activity, it is therefore important to unders tand their effects on between- as well as within-patent competition. Despite the abundance of analyses on the important role of IP regulations in limiting imitation, less seems known about the total effects of such regulations when taking into account how they affect the creative destruction across patents that takes place through between-patent competition. Without understanding the dual effects of IP-regulations on both forms of competition on innovative returns, policies aimed at stimulating R\&D may not have their intended qualitative and quantitative effects.

This paper provides a theoretical examination of the dual impacts of IP-regulations in determining the overall effects of many of the IP-interventions used to stimulate R\&D. Our main argument is that considering the impact not only on within-patent competition but also on between-patent competition matters for assessing the R\&D effects and desirability of standard intellectual property regulations. Regulations that may seem effective when only considering their impact on keeping imitation at bay may be highly ineffective when taking into account their impact on between-patent competition.

In particular, we stress that the dual effects of IP-regulations on both types of competition are likely to be offsetting. The fact that future innovation limits the rewards to current innovation implies that IP-policies aimed at stimulating R\&D may have dual- and offsetting effects on innovation. The first is the direct positive effect but the second is the indirect negative effect by stimulating between-patent competition. R\&D stimuli do not only raise the current incentive to innovate but also the incentives of producers engaging in between-patent competition. For example, an increase in an R\&D tax-break would not only make research cheaper for the innovator but would also imply that the innovator will be able to enjoy his market for a shorter duration before new patents would destroy it. Because existing explicit analyses ignores one of the dual effects, the effect on between-patent competition, it gives 
misleading implications about the effects and desirability of IP-regulations ${ }^{3}$. In particular, this dual impact of IPregulations suggests that it may be hard for the public sector to fine-tune $R \& D$ as suggested by existing formal analyses - aggregate industry R\&D may be less elastic to stimulus because of the dual impact it has.

Given the importance of both within- and between-patent competition, the paper attempts to estimate their relative impacts on innovative returns for one of the most R\&D intensive industries in the U.S.--pharmaceuticals. In 1997, R\&D-intensity ( $\& \& D$ expenditure as a percentage of net sales in R\&D-performing companies) was three times as high in the "drugs and medicines" industry as it was in the economy as a whole (10.5\% vs. $3.4 \%){ }^{4}$ Although pharmaceutical industry is often mentioned as one in which patents have their standard textbook effects, it appears that the relative importance of between-patent or therapeutic competition, rather than within-patent competition from generics, is not well understood in this industry ${ }^{5}$. Other drugs are often a larger threat to a given patented drug than the generic entry it may face down the line when the patent expires. Although generic competition may limit innovative returns, we find that less than half of drugs experience generic entry upon patent expiration. Generic entry may be unprofitable because therapeutic competition has made the imitated product obsolete. Put differently, between-patent competition limits the returns to within-patent entry. As therapeutic competition proceeds over time, more and more drugs are developed to treat a given disease, making it not only more difficult to keep an innovative return but also to generate a profit to start with.

From a measurement perspective, the pharmaceutical industry is unique in studying the two sources of competition because researchers have access to the data generated by the extensive regulatory oversight of this industry by the Food and Drug Adminis tration (FDA). ${ }^{6}$ It would be very difficult to generate the same type of data for other industries since merging sales data with patent data would be more difficult and since it would be difficult to define boundaries in which patents compete as easily as can be done with therapeutic categories of drugs. Our

\footnotetext{
${ }^{3}$ IP-regulation effects apply to other regulations that do not explicitly regulate innovation but nevertheless impact innovative returns, such as free-trade regulations. These regulations encourage globalization of markets. Globalization is often argued to stimulate $R \& D$ because larger markets enable the fixed costs of $R \& D$ to be absorbed better. However, globalization also stimulates across -patent competition through creative destruction. Larger markets do not only imply that a given innovator may benefit more, but also that the future innovators who will destroy his product will have larger incentives as well.

${ }^{4}$ Source: http://caspar.nsf.gov/nsf/srs/IndRD/NSF 01\%2D305/A-21.xls

${ }^{5}$ There exists an empirical literature that implicitly concerns both forms of competition, see e.g. Berndt el al (1995), Berndt et al (1996), and $\mathrm{Lu}$ and Comanor (1998), but not one determining their relative importance of the two in limiting innovative returns. ${ }^{6}$ According to section 505 of the Federal Food, Drug, and Cosmetic Act, "No person shall introduce or deliver for introduction into interstate commerce any new drug, unless an approval of an application... is effective with respect to such drug... Such person shall submit to the Secretary as a part of the application...full reports of investigations which have been made to show whether or not such drug is safe for use and whether such drug is effective in use." (http://www.fda.gov/opacom/laws/fdcact/fdcact5a.htm)
} 
overall findings suggest that creative destruction through between patent competition accounts for at least as much erosion of innovator returns as within-patent competition caused by patent expiration, and often considerably more. The relative importance of between-patent competition may be even higher in other high-tech industries because the average effective patent length is shorter in pharmaceuticals than it is in other industries. ${ }^{7}$ We use our estimates of the two forms of competition to assess the impact of marginal changes in patent lengths on innovative returns, such as those resulting from the Hatch-Waxman Act for US pharmaceuticals or from the international expansion of patent lives from 17 to 20 years. Although the latter represents almost an $18 \%$ increase in the patent life, it may only raise the innovative return by a couple of percent due to both discounting and between-patent competition.

The paper may be briefly outlined as follows. Section 2 discusses the dual effects of IP-regulations when both within- and between-patent competition are considered. Section 3 contains our empirical analysis on the extent to which innovative returns are limited by both forms of competition. We first consider aggregate evidence on the importance of the two sources of destruction as well as individual drug level panel data that enables us to perform a decomposition of the destruction of returns into its components destroyed creatively through between-patent competition and uncreatively through within-patent competition. Lastly, Section 4 concludes.

\section{II: PUBLIC R\&D INTERVENTIONS WITH WITHIN - AND BETWEEN-PATENT COM PETITION}

Consider a firm that invests a fixed $\operatorname{cost} f$ to obtain a new innovation with probability of success $s$ and profitability $\pi$ We represent a given $R \& D$ policy through a vector $\boldsymbol{\theta}=\left(\boldsymbol{\theta}_{c}, \boldsymbol{\theta}_{s}, \boldsymbol{\theta}_{\pi}\right)$ affecting directly these three quantities; the parameter $\boldsymbol{\theta}_{c}$ represents a public policy lowering the marginal cost of R\&D such as an R\&D taxbreak, the parameter $\boldsymbol{\theta}_{s}$ a policy raising the marginal probability of research success, such as government funded $\mathrm{NIH}$ research that complements private $\mathrm{R} \& \mathrm{D}$, and $\boldsymbol{\theta}_{\pi}$ a policy raising ex-post profitability of the innovation such as IP protections that raises barriers of within-patent competition by, for example raising the length or breadth of a patent. Thus the policy vector represents three different forms of policies that all stimulate R\&D. The expected profits under a given fixed cost $\mathrm{R} \& \mathrm{D}$ investment $f$ are given by

\footnotetext{
${ }^{7}$ In the case of pharmaceuticals, part of the patent time is devoted to the FDA approval process. According to Grabowski and Vernon (1996), the average effective patent life for drugs (including partial patent restoration provided by the Hatch-Waxman
} 


$$
s\left(f ; \boldsymbol{\theta}_{s}\right) \pi\left(\boldsymbol{\Theta}_{\pi}\right)-c\left(f ; \boldsymbol{\theta}_{c}\right)
$$

Throughout, we assume the regularity conditions $s_{f} \quad 0, s_{f f} \quad 0, c_{f} \quad 0, c_{f f} \quad 0$ so that the marginal impact (cost) of R\&D success falls (rises) with its level. The necessary first-order condition for optimal R\&D is thus

$$
s_{f}\left(f ; \boldsymbol{\theta}_{s}\right) \pi\left(\boldsymbol{\theta}_{\pi}\right)=c_{f}\left(f ; \boldsymbol{\theta}_{c}\right)
$$

Under the regularity conditions above, the necessary FOC is also sufficient for an unique optimal amount of R\&D, denoted $f(\boldsymbol{\theta})$, as a function of $\mathrm{R} \& \mathrm{D}$ policies. Using the implicit function theorem on the implicit function defining this relationship between $R \& D$ efforts and $R \& D$ policy, policy changes translate into changes in $R \& D$ according to

$$
f_{\theta_{c}}=\frac{-c_{f \theta_{c}}}{-S} \geq 0 \quad f_{\Theta_{s}}=\frac{s_{f \Theta_{s}}}{-S} \geq 0 \quad f_{\theta_{\pi s}}=\frac{s \pi_{\theta_{\pi}}}{-S} \geq 0
$$

where $-\mathrm{S}$ is positive if the second-order condition holds. The three R\&D stimuli all raises $R \& D$ in a straightforward manner. These implications do not only apply to a single monopoly firm undertaking R\&D, but also apply under certain fairly general regularity conditions to aggregate $\mathrm{R} \& \mathrm{D}$ when there are many competing firms who engage in competitive R\&D through so-called 'patent races'. Note that such races implicitly concern within-patent competition as opposed to between-patent competition stressed here. The fact that R\&D is easily stimulated or discouraged through such changes in $R \& D$ policy implies that there is a clear role for the public sector to affect $R \& D$, such as stimulating R\&D if it is under-provided due to spillovers or the fact that patents incur deadweight costs, or discouraging $R \& D$ if it is over-provided, e.g. through patent races. The crucial aspect of ignoring between patent competition is that the innovative returns or prize awarded, here denoted $\pi$, is not dependent on the amount of R\&D investment, here denoted $\mathrm{f}$, undertaken by the typical firm. This separation underlies the sunk- or fixed cost-aspect of R\&D in a standard context, but we will argue is a connection that is important for the dual effects of IP-policy.

Act) is 11-12 years, whereas the effective patent life for products other than pharmaceuticals is 18.5 years. 
Consider the innovative returns of a patent with patent length $\tau$. It faces between-patent competition from a number of competing patents $N_{t}$ at period t and within-patent competition from a number of imitating competitors $n_{t}$ after the patent has expired. Within patent competition is from producers with the same product, as opposed to

$$
\pi_{t}=\pi_{o} n_{t}^{\alpha} N_{t}^{\beta}
$$

between patent competition that is from producers with new and perhaps better products. Assume that profits in each period as a function of market structure is proportionate to the number of both types of entrants as in

$$
\pi_{t}=\pi_{o} n_{t}^{\alpha} N_{t}^{\beta}
$$

where $\pi_{o}$ is factor of proportionality and where the negative parameters $\alpha$ and $\beta$ represents the assumed proportionate affects in profits from the two types of entry. The growth of entry by between- versus within-patent competitors is assumed to be at the rates $\mathrm{b}$ and $\mathrm{w}$ for between-and within-patent competition respectively

$$
n_{t}=(1+w)^{t}, t>\tau \& N_{t}=(1+b)^{t}, t \geq 0
$$

The present value of the flow of profits from the innovation is then

$$
V \equiv \sum_{t=0}^{\infty} R^{t} \pi_{t}=\pi_{o}\left[\sum_{t=0}^{\tau}\left[R_{B}\right]^{t}+\sum_{t=\tau+1}^{\infty}\left[R_{A}\right]^{t}\right]
$$

where $\mathrm{R}$ is the discount factor and $R_{B}$ and $R_{A}$ are the "effective" discount rates before and after the patent expires defined by

$$
\begin{aligned}
& R_{B}=R(1+b)^{\alpha} \\
& R_{A}=R(1+b)^{\alpha}(1+w)^{\beta}
\end{aligned}
$$


We may write the value of the innovation as a function of the extent of within-and between patent competition as ${ }^{8}$

$$
V(w, b)=\pi_{o}\left[\frac{1-R_{B}^{\tau}}{1-R_{B}}+\frac{R_{A}^{\tau+1}}{1-R_{A}}\right]
$$

Naturally, both within- and between patent competition lowers the innovative return; $\mathrm{V}(\mathrm{b}, \mathrm{w})$ is decreasing. However, the cross derivative displays an interesting feature. A common argument about the value of patents is that imitation reduces the value of creativity--indeed this is the most common rationale offered for tolerating the distortions imposed by patent protection in the first place. However, the innovative return above implies that imitation is hurt by creativity. As can be seen by direct inspection of $\mathrm{V}$ above, this interaction occurs for two related reasons. The first is that between patent competition leaves less over to be destroyed after patent expiration by within patent competition. The second is that between patent competitors compete with within patent competitors after expiration. Therefore, within-patent competition has a smaller effect on innovative returns the larger is the extent of between-patent competition as in

$$
\frac{d^{2} V}{d w d b} \leq 0
$$

This interaction implies that changes in patent length may not affect $R \& D$ incentives in quantitatively important ways when there is substantial between-patent competition. For example, consider when the depreciation of patented profits occur at a rate of $R_{B}=(0.95)$ x $(0.85)=0.81$ being due to a 5 percent discount rate and 15 percent profit depreciation due to between patent competition. In this case even when there are no profits to be had once the patent has expired $(\mathrm{w}=-1)$ the value of the innovative return of a 17 year patent is as close as 97 percent of the value of a patent with infinite length. This implies that recent international agreements of extending patent lives from 17 to 20 years, even though that this represented close to a 18 percent increase in the patent life, it would have only increased innovative returns by a couple of percent.

${ }^{8}$ Using the fact that $\sum_{t=0}^{\tau} x^{t}=\frac{1-x^{\tau}}{1-x}$ and $\sum_{t=\tau+1}^{\infty} x^{t}=\frac{x^{\tau}}{1-x}$ for any $0<\mathrm{x}<1$. 
Now consider the effects of R\&D stimuli that not only affect the initial innovator but also the entry of within - and between patent competitors through the entry rates $w(\theta)$ and $b(\theta)$ being positively related to the $R \& D$ policies. The expected value of undertaking a given level of $R \& D$ is now

$$
s\left(f ; \boldsymbol{\Theta}_{s}\right) \mathrm{V}(\boldsymbol{\Theta})-c\left(f ; \boldsymbol{\Theta}_{c}\right)
$$

where $\mathrm{V}(\theta)=\mathrm{V}(\mathrm{b}(\theta), \mathrm{w}(\theta))$ reflects the present value of the innovative return induced by the policy vector. The effect of marginal changes in $R \& D$ policy on the level of $R \& D$ undertaken by the firm is now

$$
f_{\theta_{c}}=\frac{-c_{f \theta_{c}}+s_{f} V_{\theta_{c}}}{-S} \quad f_{\theta_{s}}=\frac{s_{f \theta_{s}} V+s_{f} V_{\theta_{s}}}{-S} \quad f_{\theta_{\pi}}=\frac{s_{f} V_{\theta_{\pi}}}{-S}
$$

Comparing these effects to those without between-patent competition we see that $R \& D$ policies have a direct effect on $R \& D$ as discussed before but in addition have indirect effects represented by how the profitability of the innovator is affected by the change in policy. The indirect effect may be offsetting or reinforcing, depending on how between-patent competition affects profits. The offsetting case is likely to occur when between-patent competition occurs through R\&D on substitute products as opposed to the reinforcing case that is likely to occur when betweenpatent competition occurs through $R \& D$ on complementary products. The complementarity case may not only operate through the demand side, but may be present through producer activities such as spillovers in advertising. However, the case of substitutability may be the most important for many IP policies. In this case, there is an offsetting indirect effect due to between-patent competition that goes against the direct effect considering only within -patent competition. Consider for example extending patent length which when only considering within patent competition would raise $R \& D$ unambiguously. However, due to its effect on between-patent competition, there is an offsetting effect. Whatever stimulates $R \& D$ today also stimulates creative destruction tomorrow and hence discourages $R \& D$ today. Indeed, aggregate $R \& D$ may fall with an $R \& D$ subsidy when product leaders cut back more in their $R \& D$ than the rise in $R \& D$ that follows from the increased incentives for creative destruction. These non-standard or neutralizing effects may imply that it is very difficult for governments to 'fine-tune' or manipulate R\&D efforts and economic growth. Public adjustments in IP-policy may be partly or fully offset by the private market in determining the rewards to inventive activity. 
The particular case of pharmaceutical innovation may illustrate these offsets. In this industry, R\&D policy consists of publicly regulated testing and marketing of drugs and devices, as e.g. through the FDA in the US. In our setting, FDA lowers the success probability $s$ by rejecting some innovations and raises the cost of R\&D c beyond private levels through distorting the cost of clinical trials. Previous analyses has stressed that FDA discourages innovation this way (see e.g. Peltzman (1973)). However, this ignores that the FDA simultaneously discourages creative destruction through between-patent competition. In some sense it serves as an improved patent by keeping out low-quality innovators that could have competed with high-quality innovators. The fact that pharmaceuticals is one of the most R\&D intensive industries may lead one to think that its negative impact on creative destruction may be an important component on the benefit side as is the direct impact of R\&D on the cost side. 


\section{EMPIRICAL ANALYSIS FOR THE US PHARMACEUTICAL INDUSTRY}

In this section we attempt to evaluate the empirical importance of the two sources of competition for the US pharmaceutical industry. In this industry, within-patent competition after patent expiration is from so-called generic manufacturers, and between-patent competition is from so-called brand-name manufacturers engaging in therapeutic competition within a given disease class. Section 3.1 documents the entry of both forms of competitors as a function of the age of the patent, section 3.2 the effects such entry has on innovative returns, and section 3.3 attempts to decompose the share of the present value of an innovation lost to the two forms of competition.

\section{A. Partitioning Drugs to Within versus Between Competition}

Even though the regulation of U.S. pharmaceuticals allows a unique opportunity to study between- versus within - patent competition, the definitions of different types of drugs are quite elaborate and cumbersome. To clarify the analysis we therefore first describe the definitions employed throughout our measurement. There are five levels of the drug classification hierarchy. These are (from highest to lowest): a drug class (e.g. antidepressants), a drug

subclass (e.g. SSRI antidepressants), a (single- or multi-ingredient) drug (e.g. sertraline), a sub-drug which specifies the active ingre dients/strength/route of administration/dosage form of a drug (e.g. sertraline $10 \mathrm{mg}$. tablet taken orally), and finally a drug product that specifies the producer of a sub-drug (e.g. sertraline 10 mg. tablet taken orally sold by Barr Laboratories). There is a distinct National Drug Code (NDC code) determined by the FDA, that is much like a bar code, for each drug product on the market.

According to the medical information company Multum's Lexicon, as of September 2000 there were 2123 drugs with 1830 different ingredients, thereby making most drugs single-ingredient drugs but allowing for some with multiple ingredient drugs. There were just below 3 times as many, 6200, sub-drugs, and about 35 times as many, about 70,000, drug products (different NDC codes). The magnitude of drug products stems from the fact that there were about 683 drug producers (manufacturers, redistributors, and repackagers). For economic purposes, sub-drugs may be close but not perfect substitutes but drug products within the same sub-drug are certainly close to perfect substitutes. 
Our analysis refers to competition between patents as competition between drugs in the same drug class (e.g. competition between Lipitor, Zocor, and other cholesterol-lowering drugs). We refer to competition within patents as competition between producers of the same drug (e.g. competition between Andrx, Aventis, Biovail, and other producers of the drug diltiazem).

\section{B. Estimates of average rates of entry by age of drug}

Figure 1 presents data on the typical extent of within-patent competition-n, the average number of producers of a drug-and between-patent competition $-\mathrm{N}$, the average number of drugs within a drug's class—by age of the drug (number of years since FDA approval) during the period 1982-2001. ${ }^{9}$ Figure 1 reveals that there is a substantial amount of between-patent competition for a drug even upon entry, about 25 drugs already exist in the class, as well as through additional entry while on patent. On the other hand, within-patent competition increases only by less than a single drug within the first 10 years. Here are a few summary statistics (We explain below how these statistics were calculated).

\begin{tabular}{|r|r|l|}
\hline & $\begin{array}{l}\text { average } \\
\text { number of } \\
\text { producers } \\
\text { of a drug }\end{array}$ & $\begin{array}{l}\text { average } \\
\text { number of } \\
\text { drugs } \\
\text { within a } \\
\text { drug's class }\end{array}$ \\
\hline 0 & 1.02 & 24.9 \\
\hline 5 & 1.17 & 27.9 \\
\hline 10 & 1.91 & 31.5 \\
\hline 14 & 2.78 & 33.9 \\
\hline
\end{tabular}

The purpose of this section is to more systematically assess the entry patterns of Figure 1, what effect they have on measures related to the innovative return of a drug, and when those effects are taken into account, and to measure how the two forms of competition compare in reducing the innovative return. To preview, our main finding will be that between-patent competition is many times more harmful than within-patent competition in reducing the present value of sales for a given drug.

\footnotetext{
${ }^{9}$ FDA approval dates prior to 1982 are censored in the Orange Book.
} 


\section{Within-patent entry}

Our first source of data on the general pattern of within-patent entry in the pharmaceutical industry is the The Orange Book of the Food and Drug Administration (FDA). It lists all approved prescription drugs, including brand-name drugs that represent between-patent competition and generic drugs that represent within-patent competition. ${ }^{10}$ The Orange Book offers two different ways to estimate the rate of entry of producers into markets for particular pharmaceutical products, one at the drug level and one at the ingredient level.

As The Orange Book records the date of FDA approval as well as whether generic entry has occurred ${ }^{11}$, it allows us to estimate an age-profile of generic entry. More precisely, the presence of so-called therapeutic equivalence (TE) codes in the Book indicates approval of a generic version of the drug. This allows us to measure, for each of the 4195 drugs represented in the Book: (1) the year the product was first approved by the FDA, and (2) whether any records of that product contained a TE-code that would occur under generic entry. We then calculated the proportion of drugs that had experienced entry by age as plotted in Figure 2 where the age of a drug is defined as the calendar year less the FDA drug approval year.

\section{Insert Figure 2}

The proportion of drugs with generic entry rises from $3 \%$ at age 0 to $11 \%$ at age 5 , and increases by an average of 400 basis points per year until age $18 .^{12}$ The profile is a step-function for a given drug, but due to the variation in effective patent lives, aggregation implies a close to continuous function. Although the age-imitation probability profile shown in Figure 2 is rather noisy, it indicates that within-patent competition is fairly limited, especially when compared to between-patent entry documented in later sections.

\footnotetext{
${ }^{10}$ The web-site of the book is (http://www.fda.gov/cder/orange/default.htm)

${ }^{11}$ More precisely, each record in the Approved Drug Products file of The Book contains the active ingredient(s) for the product, dosage, route of administration, strength, the firm holding legal responsibility for the new drug application, and the approval Date (The date the product was approved as stated in the FDA approval letter to the applicant. Products approved prior to the January 1, 1982 contain the phrase: "Approved prior to Jan 1, 1982".), and the therapeutic equivalence (TE) code; the TE Code indicates the therapeutic equivalence rating of generic to brand-name drugs.
} 
There is an alternative, and apparently more reliable, way to measure the rate of within patent entry. For each of the 1520 ingredients identified in the Approved Drug Products file of the Orange Book, we determined the first date at which a product containing that drug was approved. As an example, consider below the data for the antiarrhythmic drug amiodarone hydrochloride:

\begin{tabular}{|l|l|}
\hline Year approved & Applicant \\
\hline 1985 & Wyeth Ayerst \\
\hline 1998 & Copley Pharm \\
\hline 1998 & Eon \\
\hline 1998 & Upsher Smith \\
\hline 1999 & Alphapharm \\
\hline 1999 & Novopharm \\
\hline
\end{tabular}

For each drug first approved in 1982 or later, we computed the number of producers representing the within patent entrants (n) that were approved up until age t. To determine the typical rates of increase of the number of entrants over the life cycle of a drug, we estimated the following regression:

$$
\ln n_{i t}=\alpha_{i}+\delta_{t}+u_{i t}
$$

where $n_{i t}$ is the number of producers approved to market drug i up until age t, $\alpha_{i}$ is a fixed effect for drug i, and $\delta_{t}$ is a fixed effect for age t. Hence $\left(\delta_{5}-\delta_{0}\right)$, for example, represents the mean log change in the number of applicants between age 0 and age 5 .

Note that within patent entry occurs before statutory industry patent lengths, historically 17 years but currently 20 years, in the pharmaceutical industry. This is because part of that length is devoted to FDA approval of the drug. As a consequence, a non-degenerate distribution of ages of drugs from the time they are marketed until within -patent entry occurs. Nevertheless, the data reveals that a drug is fairly well-protected from early entry, after which the probability of entry rises exponentially as the drug age approaches the statutory patent length. However, as all drugs observed had effective patent lengths below 18 years, when the entry probability is slightly larger than a half, the average probability of within patent competition at the time of patent expiration is below a half.

\footnotetext{
${ }^{12}$ Due to the censoring of approval dates prior to 1982 in The Orange Book, we cannot compute the proportion by single year of
} 


\section{Between-patent entry}

To assess between patent competition empirically, one has to define what the relevant markets are in which patents compete, potentially interpreted as patents across which demand exhibits zero cross-price elasticities. Drugs are a very useful product market to study in this respect because the disease categories into which so called therapeutic competition occurs are relatively well defined compared to other markets. To define therapeutic classes in which patents compete, we used the The National Drug Code (NDC) Directory ${ }^{13}$. The NDC serves as a universal product identifier for human drugs. The Directory uses a general therapeutic or pharmacological classification scheme for drug products reported to the FDA under the provisions of the Drug Listing Act. The classification scheme used was based on the AMA Drug Evaluations Subscription and generally follows the organization of material in that publication. The drug class for each product was determined by the labeled indication. The drug class codes and their definitions are listed in Appendix Table 1. We linked two NDC files to obtain a mapping from drugs (ingredients) to drug classes. Some drugs appear in multiple drug classes. When this occurred, we assigned the drug to the drug class with which it was most frequently linked. We then linked this list of drugs to the list of drugs obtained from The Orange Book (described above), which included the FDA approval date of the drug. Finally, we sorted the resulting list, by drug class and approval date. This list shows the history of new drug approvals, by drug class. As an example, here are the results for drug class 1944, antihistamines:

\begin{tabular}{|l|l|}
\hline Date approved & Ingredient \\
\hline Before $1 / 1 / 82$ & Astemizole \\
\hline Before $1 / 1 / 82$ & Clemastine \\
\hline Before $1 / 1 / 82$ & Cyproheptadine \\
\hline Before $1 / 1 / 82$ & Hydroxyzine Monohydrochloride \\
\hline Before $1 / 1 / 82$ & Terfenadine \\
\hline Before $1 / 1 / 82$ & Tripelennamine \\
\hline $1 / 25 / 82$ & Diphenhydramine Hydrochloride \\
\hline $7 / 7 / 82$ & Promethazine Hydrochloride \\
\hline $7 / 19 / 82$ & Dexchlorpheniramine Maleate \\
\hline $4 / 12 / 93$ & Loratadine \\
\hline $12 / 8 / 95$ & Cetirizine Hydrochloride \\
\hline $7 / 25 / 96$ & Fexofenadine Hydrochloride \\
\hline $11 / 1 / 96$ & Azelastine Hydrochloride \\
\hline
\end{tabular}

age for ages greater than 18. For the 1689 products with first FDA approval dates prior to 1982 (age > 18), the proportion of products indicating generic entry is $57 \%$.

${ }_{13} \mathrm{http}: / /$ www.fda.gov/cder/ndc/index.htm 
Using this information, we computed the number of drugs in a given drug's class representing the between-patent competition $(\mathrm{N})$, by age of the drug defined as before by the calendar year less FDA drug approval year. We then estimated an equation similar to eq. (1), substituting $\left(\ln N_{i t}\right)$ for $\left(\ln n_{i t}\right)$.

Estimates of the coefficients of the normalized age dummies $\left(\delta_{t}-\delta_{0}\right)$ are reported in Table 1 and plotted in Figure $3 .{ }^{14}$ In the first 3 years, the mean number of applicants increases by just $1.2 \%$, while the mean number of drugs in the class increases by $12.6 \%$. In the next 3 years, the mean number of applicants accelerates significantly, and the mean number of drugs in the class decelerates somewhat; by year 6 , the mean number of applicants is $9.5 \%$ larger than it was at birth, while the mean number of drugs in the class is $20.9 \%$ larger than it was at birth. The increase in the number of drugs in the class remains higher than the increase in the number of applicants for the drug until year $14 .^{15}$

These calculations indicate that in the first 13 years of a drug's life, and especially in the earlier years, the number of between patent competitors in the drug's class typically increases more, in percentage terms, than the number of within patent competitors approved to market the same drug. Of course, the fact that the rate of betweenpatent entry is higher does not necessarily mean that between-patent entry has a larger impact on innovator sales than within-patent entry. To determine the relative magnitudes of the impacts of between-and within-patent entry on innovator sales, we need to estimate a model of innovator sales as a function of the two kinds of entry.

\section{Estimating the effects of entry on innovator drug sales growth}

In this section we attempt to estimate the effects of both forms of patent competition on the sales of a new drug.

\footnotetext{
${ }^{14} \mathrm{The} \ln (\mathrm{n})$ regression is based on data for 538 ingredients; the standard errors of the $\delta$ estimates range between .056 and .060. The $\ln (\mathrm{N})$ regression is based on data for 725 ingredients (sample size 7713); the standard errors of the $\delta_{\mathrm{t}}$ estimates range between .014 and .016 . The mean value of $\mathrm{N}$ at age 0 is 24.9 .

${ }^{15}$ The average rate of growth of $\mathrm{N}$ from year 0 to year 16 is $2.7 \%(=42.5 \%$ / 16). This estimate is about $50 \%$ higher than the growth rate of the aggregate stock of ingredients between 1986 and 2000. According to Multum Lexicon 9/17/00 edition, there were 1830 active ingredients. During the period January 1986-August 2000, the FDA approved a total of 417 new molecular entities. This implies that there were $1413(=1830-417)$ active ingredients at the beginning of 1986 , and that the average annual growth rate of the stock during the period was $1.72 \%$.
} 


\section{The Data}

Ideally, to estimate the effects of between- and within -patent competition, one would like to have a complete set of longitudinal data on innovator sales, by product. Unfortunately, we were unable to obtain data on sales to all customers. However comprehensive data on Medicaid sales during 1996-1999 are available from Medicaid State Drug Utilization files published by HCFA. ${ }^{16}$ Medicaid accounts for about one-sixth of national prescription drug expenditure. $^{17}$

\section{Insert Figure 4}

As Figure 4 indicates, the period covered by the Medicaid data is a good one in which to study the effects of entry of new drugs because there was substantial entry of new drugs. Between 1986 and 1995, the average annual number of drugs, or new molecular entities (NMEs), approved by the FDA was 24. Between 1996 and 1999 , it was 39-a $65 \%$ increase. This surge in approvals is partly attributable to a reduction of FDA approval times, which was made possible by the 1992 Prescription Drug User Fee Act. Between 1992 and 1998, mean NME approval time declined $61 \%$, fro m 30 months to under 12 months.

The State Drug Utilization Data report the total reimbursed amount in dollars, and two quantity measures -total units reimbursed ${ }^{18}$, and total number of prescriptions--by product and state, quarterly during the period 19961999. We constructed from these two different price measures: price per prescription, and price per unit (where tablet is an example of a unit). We downloaded about 200 Medicaid state drug utilization files (one per state per year, 1996-1999), containing about 7 million records. We then aggregated the data up to the national level, so that we had quarterly data for 16 quarters on about 42,000 products (NDC codes)--about half a million observations. We linked these data to HCFA's Drug Product Data file ${ }^{19}$, which indicates whether each product in the entire formulary of products available under the Medicaid Drug Rebate program is an innovator or non-innovator product.

\footnotetext{
${ }^{16}$ See http://www.hcfa.gov/medicaid/drugs/drug5.htm

${ }^{17}$ Source: HCFA National Health Care Expenditures (http://www.hcfa.gov/stats/nhe-oact/).

${ }^{18}$ Units refers to the number of tablets, capsules, and the like.

19 (http://www.hcfa.gov/medicaid/drugs/drug6.htm)
} 
Table 2 reports summary statistics based on the Medicaid State Drug Utilization Data. The total reimbursed amount is about $20 \%$ lower than the Medicaid expenditures reported in the National Health Care Expenditures statistics. The micro data indicate that Medicaid reimbursed about $\$ 47$ billion during the period $1996-$ 1999, and paid for about 317 million prescriptions per year. ${ }^{20}$ The average price (amount reimbursed per prescription) increased from $\$ 31.01$ to $\$ 44.04$ from 1996 to $1999 .^{21}$

In general, each state Medicaid program pays a rebated amount below the pharmacy average wholesale price (AWP) paid in the private sector. Part of this rebate is mandated by federal law, being $15.1 \%$ for patented (brand name) drugs and $11 \%$ for non-patented (generic) drugs. However, this mandatory rebate is not always binding in the sense that prices may be charged below it, and differentially so across states. Our average Medicaid prescription prices are fairly close to prices that can be computed from other sources.

\section{Insert Table 3}

Table 3 reports statistics computed from the 1996 Medical Expenditure Panel Survey (MEPS) Prescribed Medicine Events file on the number and average price of Medicaid and non-Medicaid prescriptions in 1996. That file reports the total amount paid for the prescription, and the amount paid by various payers, including Medicaid. A Medicaid prescription is defined as one in which there was any payment by Medicaid. The average price of a prescription was $\$ 32.88$, and there was very little difference between the average price of Medicaid and non-Medicaid prescriptions. This price is about $6 \%$ higher than the average price computed from the Medicaid State Drug Utilization Data files.

IMS data on all U.S. prescriptions in 1999, as reported in Pharmacy Times ${ }^{22}$, provide another basis for comparison. $^{23}$ According to IMS, total 1999 sales in the U.S. Prescription Market were $\$ 124,835,595,000$, and there were $2,821,770,000$ total prescriptions dispensed. ${ }^{24}$ Hence the average price of a prescription was \$44.24 in 1999 . This differs by only $0.5 \%$ from the average 1999 price computed from the Medicaid State Drug Utilization Data files, \$44.04. This evidence suggests that the Medicaid program accounts for a significant share of total U.S.

\footnotetext{
${ }^{20}$ According to HCFA data on National Health Expenditures By Type Of Service And Source Of Funds, total Medicaid drug expenditure was about $25 \%$ higher: $\$ 11.1$ billion in $1996, \$ 13.0$ billion in 1997 , and $\$ 15.5$ billion in 1998 . See http://www.hcfa.gov/stats/nhe-oact/tables/nhe98.csv.

${ }^{21}$ Most of this $42 \%$ increase in the average price was due to changing product mix, rather than increasing prices of given products.

${ }^{22}$ http://www.pharmacytimes.com/

${ }^{23}$ Unfortunately, similar data are not available for previous years.
} 
pharmaceutical sales, and that drugs purchased under Medicaid are fairly representative of all U.S. drug transactions, at least in terms of price. Therefore estimates of the effect of within- and between-patent competition on Medicaid sales are likely to be informative about their effects on pharmaceutical sales in general. ${ }^{25}$

\section{Estimates}

We obtain these estimates by estimating models of the following form:

$$
\Delta \ln \mathrm{Q}_{\mathrm{jkt}}=\alpha \ln \mathrm{N}_{\mathrm{jt}}+\beta \ln \mathrm{n}_{\mathrm{jt}}+\alpha_{\mathrm{jk}}+\delta_{\mathrm{t}}+\mathrm{u}_{\mathrm{jkt}}
$$

where $Q_{j k t}$ is the quantity or value of product $j$ sold by firm $k$ in quarter $t, N_{j t}$ is the number of between-patent competitors in the same drug class as drug $\mathrm{j}$ in quarter $\mathrm{t}$, and $\mathrm{n}_{\mathrm{jt}}$ is the number of within-patent competitors in quarter t. This log-linear specification is appropriate if, as we believe, there are diminishing marginal effects of entry on incumbent sales, e.g. if the first entrant's sales are reduced more by entry of a second firm than they are by entry of a third firm.

To calculate $\mathrm{N}$ and $\mathrm{n}$ on a quarterly basis for tens of thousands of products, we used Multum's Lexicon, which features a hierarchical classification system that links similar products sold by different manufacturers and organizes drugs into drug classes. ${ }^{26}$

Insert Table 4

Estimates of eq. (2), by product type (innovator vs. non-innovator), are presented in Table 4. The estimates are based on a sample of over 388 thousand observations on almost 32 thousand products. The dependent variable in column 1 is quarterly growth in the number of units reimbursed. The estimates indicate that both kinds of entry

\footnotetext{
${ }^{24}$ This implies that $12 \%$ of all U.S. prescriptions were reimbursed by Medicaid.

${ }^{25}$ Analysis of 1997 Medical Expenditure Panel Survey data indicates that generics account for a higher share of Medicaid prescriptions than they do of non-Medicaid prescriptions (45\% vs. 37\%). Hence our estimates may understate the relative importance of between-patent competition in the overall market for pharmaceuticals.

${ }^{26}$ Because entry — especially entry of new, patented products — is likely to occur in markets experiencing high demand growth, one would not necessarily expect $\mathrm{N}$ to be negatively correlated with thelevel of sales. When the dependent variable is the growth in value or quantity, as in eq. (2), the fixed product effects $\alpha_{j k}$ control for unobserved demand growth, which is presumably positively correlated with both sales growth and entry.
} 
reduce the growth of innovator sales, although the between-patent entry coefficient is two and a half times as large as the within-patent entry coefficient. ${ }^{27}$

Columns 2 and 3 reveal that similar estimates are obtained when the dependent variable is growth in the number of prescriptions or growth in total dollar amount reimbursed. ${ }^{28}$ Similarity of the coefficients of the quantity and value regressions implies that neither type of entry has much effect on innovator product prices. This is consistent with previous studies, which have found little effect of generic entry on branded (innovator) drug prices.

We can estimate the year-by-year reductions in innovator sales growth due to within- and between-patent entry by combining the estimates of eq. (1) (plotted in Figure 3) and eq. (2) (shown in the first column of Table 4). In particular, we multiply the first column of Table 1 by the $\ln (\mathrm{n})$ coefficient $(-.068)$, and the second column of

Table 1 by the $\ln (\mathrm{N})$ coefficient ( -.194). The estimated reductions in innovator sales growth are plotted in Figure 5 .

\section{[FIGURE 5 INSERTED HERE]}

The estimates imply that throughout the first 16 years, and especially in the early years, between-patent entry reduces innovator sales growth much more than within-patent entry. After 5 years, between-patent entry has reduced innovator sales growth by $3.6 \%$, while within-patent entry has only reduced it by $0.4 \%$. At 10 years, the estimated reductions are $5.9 \%$ and $1.4 \%$, respectively. The gap begins to narrow after year 13 , but in year 16 , within -patent entry has still reduced sales growth less than between-patent entry: $4.1 \%$ vs. $8.2 \%$.

\section{Decomposing Loss in Innovative Returns from Within- versus Between Patent Competition}

\footnotetext{
${ }^{27}$ The effect of entry on innovator sales growth is our principal concern, but we also report in Table 4, for purposes of comparison, corresponding estimates for non-innovator drugs. Both entry variables have significant negative coefficients in the non-innovator product regression, but the relative magnitude of the coefficients is just about the reverse of what it was in the innovator product regression. Thecoefficient on within-patent entry is about three times as large as the coefficient on betweenpatent entry. Evidently, entry of additional generic firms is a greater threat to incumbent generic firms than it is to the innovator. But entry of new brands is a far greater threat to innovators than it is to imitators.

${ }^{28}$ It is also not inconsistent with $\mathrm{Lu}$ and Comanor's (1998) findings. Let $\mathrm{P}_{\mathrm{i}}(\mathrm{i}=1,2, \ldots)$ represent the price of the $i^{\text {th }}$ branded drug entering a drug class: $\mathrm{P}_{1}$ is the price of the first entrant, $\mathrm{P}_{2}$ is the price of the second entrant, etc. Lu and Comanor examined the relationship between $\mathrm{P}_{\mathrm{N}}$ and $\mathrm{N}$, and found that $\mathrm{P}_{\mathrm{N}}$ is inversely related to $\mathrm{N}$ : later entrants tend to charge lower prices. We are implicitly examining the effect of entry of the Nthbranded drug (an increase from $\mathrm{N}-1$ to $\mathrm{N}$ in the number of members of the drug class $)$ on the mean of $\left(\mathrm{P}_{1}, \mathrm{P}_{2}, \ldots, \mathrm{P}_{\mathrm{N}-1}\right)$.
} 
The estimates plotted in Figure 5 can be used to calculate the effects of within-and between-patent entry during years $0-16$ on the present dis counted value of sales during those years, evaluated at age 0 , i.e. the date of FDA approval. Consider the counterfactual sales in the absence of any entry in which case within- or betweenpatent entry at all ages was set to zero: $\Delta \mathrm{n}=\Delta \mathrm{N}=0$. Now assume that annual sales was a thousand for all ages until expiration; $Y_{t}=\$ 1000$ for $t=0,1,2, \ldots, 16$. Use the estimated entry rates multiplied by their estimated effects on sales to calculate two new sales profiles by age; one when there is only within-patent competition $(\Delta \mathrm{n}$ as observed, $\Delta \mathrm{N}=0$ ) and another when there is only between patent competition ( $\Delta \mathrm{N}$ as observed, $\Delta \mathrm{n}=0)$. Our estimates imply that within-patent entry alone reduces sales in years 5,10 , and 15 , to $\$ 993, \$ 943$, and $\$ 828$ respectively, and that between-patent entry alone reduces sales in years 5,10 , and 15 , to $\$ 887, \$ 686$, and $\$ 476$, respectively. In other words, between-patent entry reduces sales in year 15 by more than twice as much as within-patent entry. Using a $5 \%$ interest rate, we estimate that within-patent entry alone reduces the PDV of year 0-16 sales by $4 \%$ ( $\$ 11,313$ vs. $\$ 11,838$ ), and that between-patent entry alone reduces the PDV of year 0-16 sales by $17 \%$ (\$9420 vs $\$ 11,838$ ). Between-patent entry has about four times as large an effect on the PDV of year 0-16 sales as within-patent entry. This finding is not very sensitive to the choice of interest rate. If we use a $3 \%$ interest rate, the reductions in the PDV of year 0-16 sales from within - and between-patent entry are 5\% and 18\%, respectively; if we use a $7 \%$ interest rate, they are $4 \%$ and $16 \%$. Thus it appears that our estimate suggests that between-patent competition is more important in affecting this measure of an innovative return than is within patent competition.

\section{E. IMPLIED EFFECTS OF MARGINAL CHANGES IN THE LENGTHS OF PATENTS}

We use our estimates of the impact on innovative returns for two forms of competition to assess the impact of marginal changes in patent lengths on innovative returns, such as those resulting from the Hatch-Waxman Act for US pharmaceuticals or from the international expansion of patent lives from 17 to 20 years.

\section{[FIGURE 6 INSERTED HERE]}

More precisely, suppose that the within-patent entry profile in Figure 5 was shifted to the left by either 1 year, 3 years, or 5 years. We assume that after 16 years, the within-patent entry profile continues to decline by $-0.8 \%$ per year. The effect of this shift on the PDV of innovator sales depends on the joint discounting induced by the rate of 
between-patent entry and the rate of interest. Now consider three different sets of values of between-patent entry-baseline as estimated in Figure 5, 50\% decrease from baseline, and 50\% increase from baseline-and four different interest rates: $0,3,5$, and 7\%. Figure 6 depicts the estimated percentage reductions in PDV of innovator sales resulting from these 1-year, 3 -year, and 5-year acceleration of patent expiration, under the different scenarios. A useful upper bound on the loss (the percentage reduction in the PDV) is the corresponding percentage reduction in the patent life itself. However, as seen from Figure 6, often the actual loss is far below that upper bound.

\section{Concluding Remarks}

A patent only protects an innovator from others producing the same product, but it does not protect him from others producing new products under new patents. Therefore, one may divide up the source of competition facing an innovator as into within-patent competition which results from production of the same product and between-patent competition which results from production of products on other patents. Previous analyses, whether theoretical or empirical, has focused on the effects of IP-regulations on within-patent competition, by showing how protecting innovative returns from imitators affects R\&D incentives. However, the importance of between-patent competition in affecting innovative returns, particularly through creative destruction in the many high-tech industries being central to overall economic progress, suggests that a fuller understanding of IP-regulations takes into account its effects on between-patent competition. We showed how between patent competition may respond to IP-regulations in ways that many times offset their primary effects of stimulating R\&D.

We attempted to estimate the relative magnitudes of the two sources of competition in limiting innovative returns in the U.S. pharmaceuticals market. In this market within-patent competition from so called generic producers has been over-emphasized relative to competition between-patents through so called therapeutic competition. We estimated that between-patent competition, most of which occurs while a drug is under patent, costs the innovator at least as much as within-patent competition, which cannot occur until a drug is off patent. The reduction in the present discounted value of the innovator's sales from between patent competition appears to be at least as large as the reduction from competition within patents, and may be much larger. This is suggestive of that the statutory monopoly awarded through a patent does not always confer great monopoly power in the usual sense of being able to raise price without substantial substitution 
There were several weaknesses in the analysis that may be addressed more appropriately in future analyses. First, the degree to which selection affects the relative importance of the two types of competition should be considered more fully. If entry off- and on-patent are differentially correlated with unobservable determinants of sales, such as demand shocks, then the method proposed to estimate the relative importance of the two may be biased.

Although the effects of limiting within-patent competition may be small due to both discounting and between-patent competition, the effects of limiting between-patent competition may be large. An interesting case that illustrates this is the U.S. Orphan Drug Act of 1983. This act added a 7-year exclusivity right to a class of drugs for rare diseases, in addition to additional tax-breaks for $\mathrm{R} \& \mathrm{D}$ expenditure. It thereby provided a unique reduction in between-patent competition, without the offsetting effects discussed in this paper for other types of stimuli. The Act dramatically raised both $R \& D$ spending and entry of orphan drugs, facts that may be a testament to the relative importance of between-, rather than within-, patent competition in eliminating innovative returns.

Given the importance of between patent competition in the pharmaceutical industry, and the fact that it seems likely to be even more important for other high-tech industries that may be central to overall economic progress, we hope that future analyses will shed more light on its impact on optimal IP-policies. The discussed feedback effects across patents induced by standard IP-measures suggests that firm-level effects may be different than industry-level effects. Current empirical work on the effects of R\&D stimuli on research activity, see e.g. the review by Hall and Van Reenen (1999), does not consider the differences in firm-vs industry level effects, nor the different impact such stimuli may have on within versus between patent competition. A better understanding is needed of the ways in which IP-regulations affects not only the incentives to imitate through within patent competition, but also the incentives to generate new intellectual property rights and the resulting feedback effects those new rights have on innovation in the first place. 


\section{References}

[1] Aghion, P., and Peter Howitt (1992), "A Model of Growth Through Creative Destruction”, Econometrica 60 (2), 323-351.

[2] Berndt, Ernst R., Iain M. Cockburn, and Zvi Griliches, (1996), "Pharmaceutical Innovations and Market Dynamics: Tracking Effects on Price Indexes for Antidepressant Drugs" Brookings Papers on Economic Activity. Microeconomics, Vol. 1996, pp. 133-188.

[3] Berndt, Ernst R., Linda Bui, David R. Reiley, Glen L. Urban, (1995), “Information, Marketing, and Pricing in the U.S. Antiulcer Drug Market “ The American Economic Review 85(2), Papers and Proceedings, May, pp. 100-105.

[4] Green, Jerry, and Suzanne Scotchmer, (1995), ”On The Division of Profits In Sequential Innovation", RAND Journal of Economic, 26, 20-33..

[5] Gallini, Nancy, (1992), "Patent Policy and Costly Imitation", RAND Journal of Economics, 23, p. $52-63$.

[6] Gilbert, Richard and Carl Shapiro, (1990), “Optimal Patent Length and Breadth”, RAND Journal of Economics, 21, p. 106-112.

[7] Grabowski, Henry, and John Vernon (1996), "Longer Patents for Increased Generic Competition in the US: The Waxman-Hatch Act After One Decade," PharmacoEconomics 10, Suppl. 2, pp. $110-123$.

[8] Hall, B., J. Van Reenen, (1999), "How effective are fiscal incentives for R\&D? A Review of The Evidence”, NBER Working Paper No 7098, Cambridge, MA.

[9] Horstmann, Ignatius, Glenn MacDonald and Alan Slivinski (1993), "Patents as Information Transfer Mechanisms: To Patent or (Maybe) Not to Patent", Journal of Political Economy

[10] Judd, Kenneth, (1985), “On the Performance of Patents", Econometrica, 53, p.567-585.

[11] Klemperer, Paul, (1990), "How Broad Should the Scope of Patent Protection Be?", RAND Journal of Economics, 21, p. 113-130. 
[12] Lu, J.Z, and W.S. Comanor, (1998), "Strategic Pricing of New Pharmaceuticals", Review of Economics and Statistics, 80(1), 108-118.

[13] Nordhaus, William, (1969), Invention, Growth, and Welfare, Cambridge: MIT Press.

[14] Peltzman, Sam, (1973), “An Evaluation of Consumer Protection Legislation: The 1962 Drug Amendments" The Journal of Political Economy, Vol. 81, No. 5., pp. 1049-1091.

[15] Pakes, Ariel, (1985), "Patents as Options: Some Estimates of The Value of Holding European Patent Stocks", Econometrica, v 54, 755-84.

[16] Scotchmer, Suzanne, (1996), "Protection Early Innovators: Should Second-Generation Products be Patentable?," RAND Journal of Economics, 27, p. 322-331.

[17] Wright, Brian, (1983), “The Economics of Invention Incentives: Patents, Prizes, and Research Contracts", American Economic Review 73. 


\section{Figure 1}

Typical extent of within- and between-patent competition, by age of the drug, 1982-2001

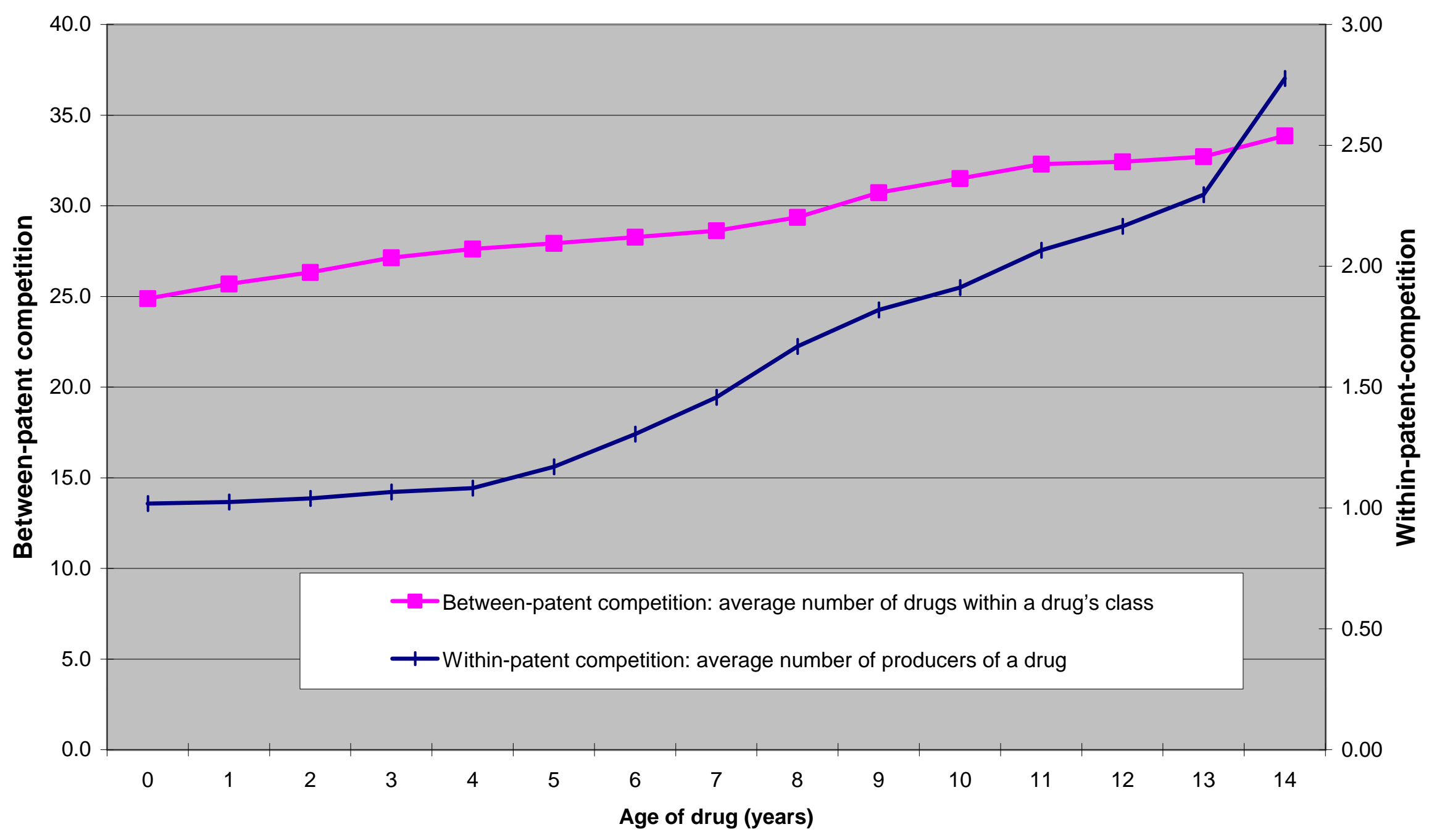


Figure 2

Proportion of Products with Therapeutic Equivalence Code, by age, 1982-2001

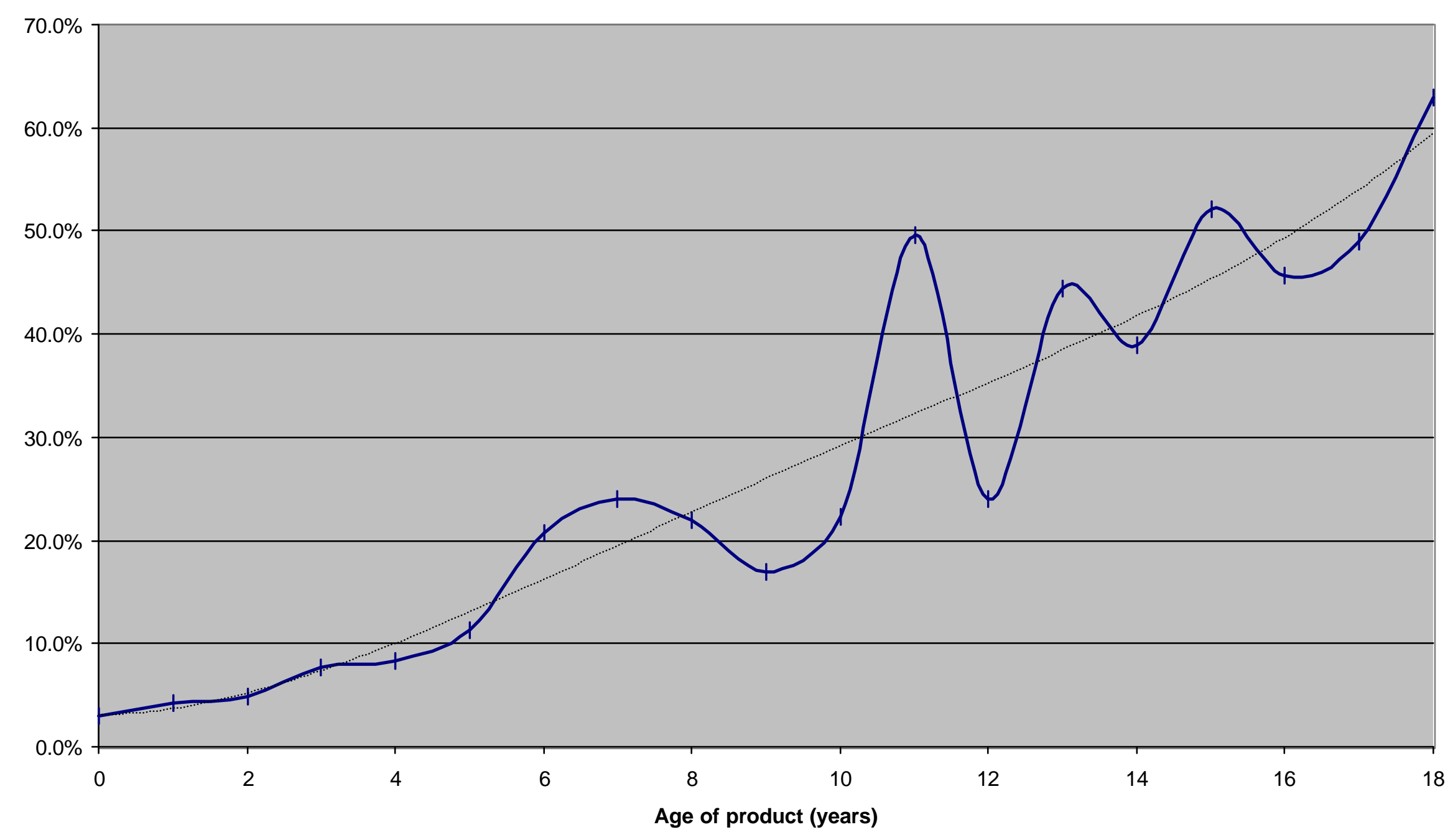


Figure 3

Number of drugs approved in class, and

number of applicants approved to market drug, by drug age, 1982-2001

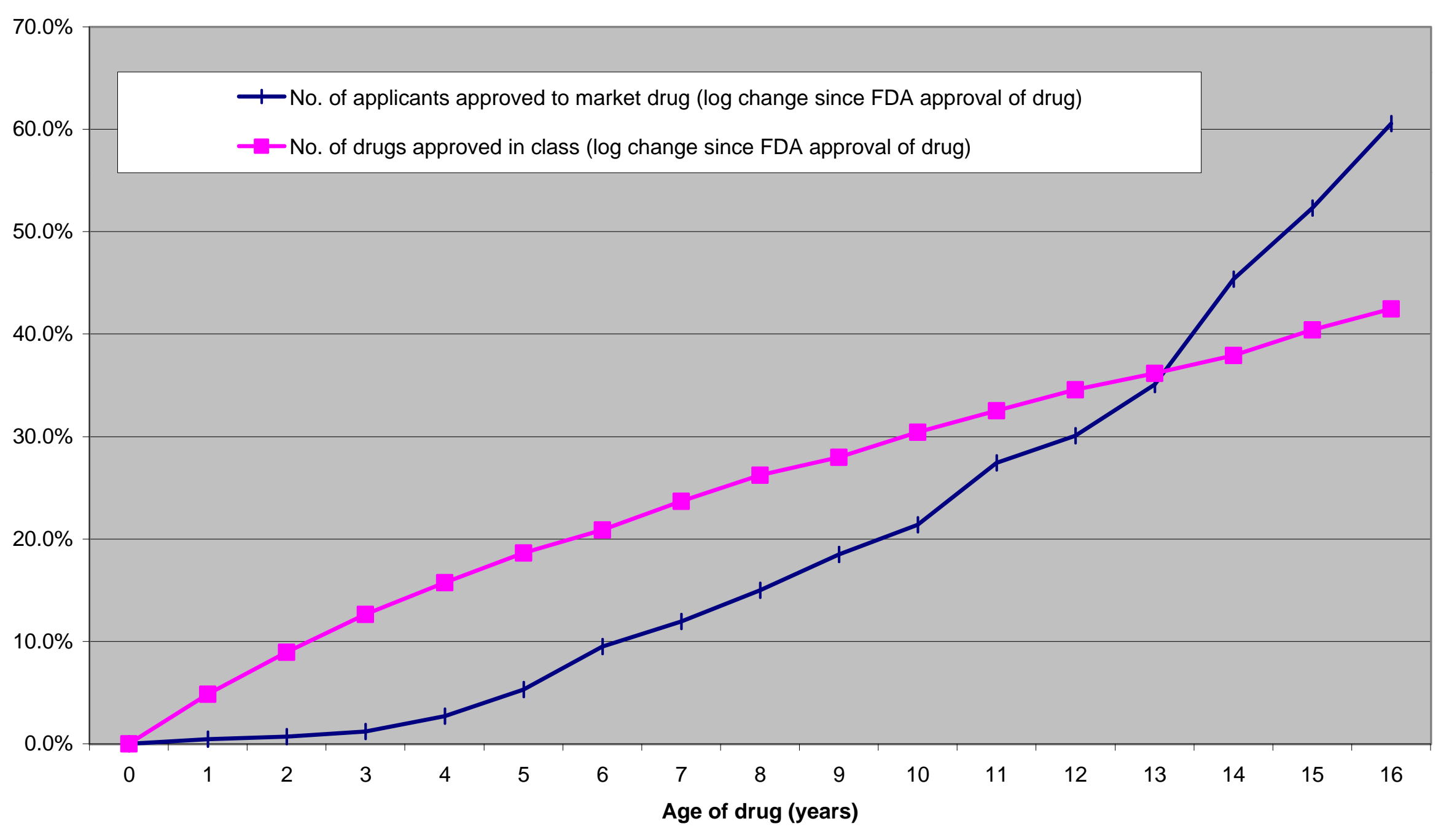


Figure 4

Number of New Molecular Entities Approved by the FDA, 1986-1999

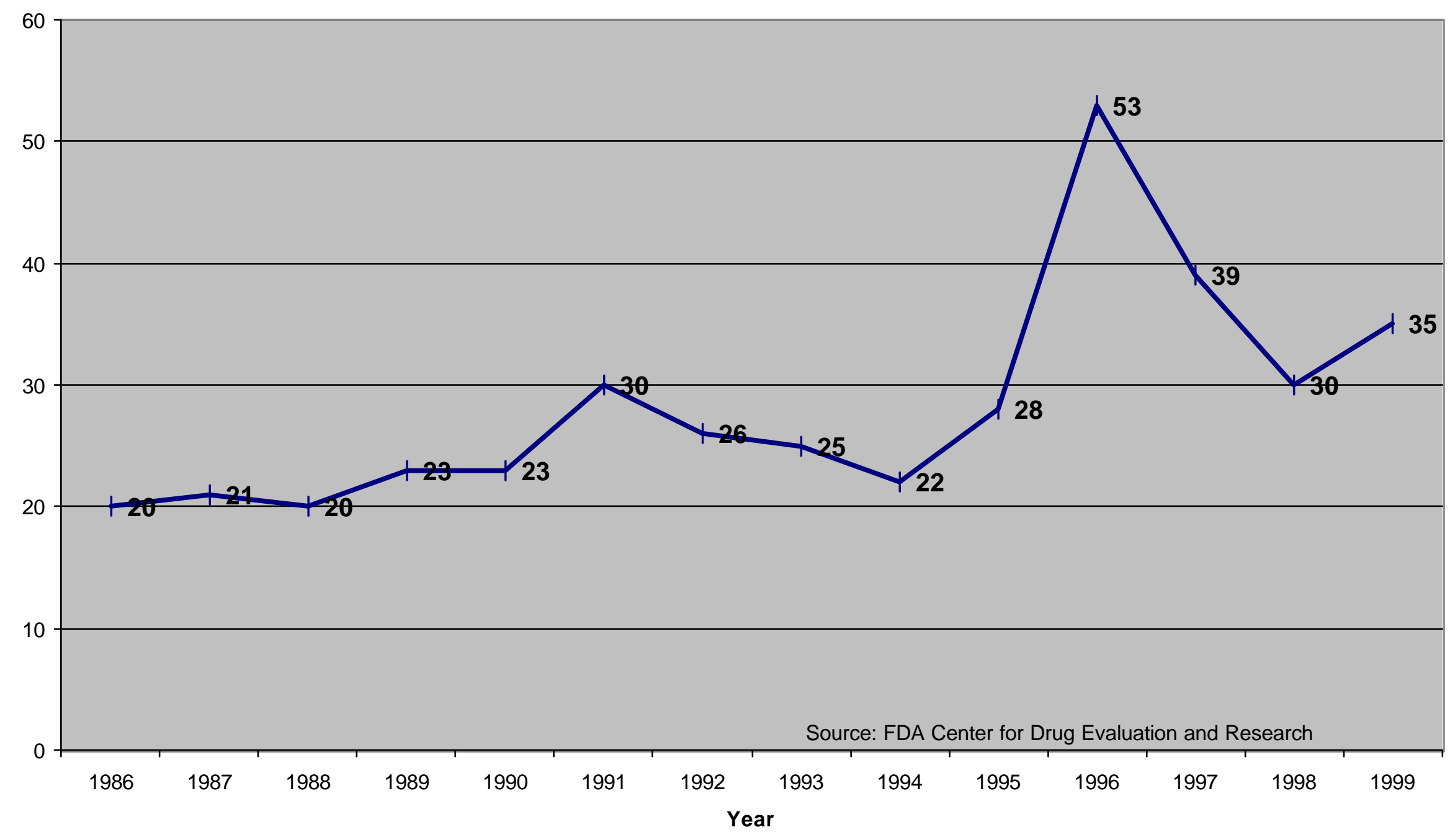


Figure 5

Estimated reduction in innovator sales growth due to within- and between-patent entry

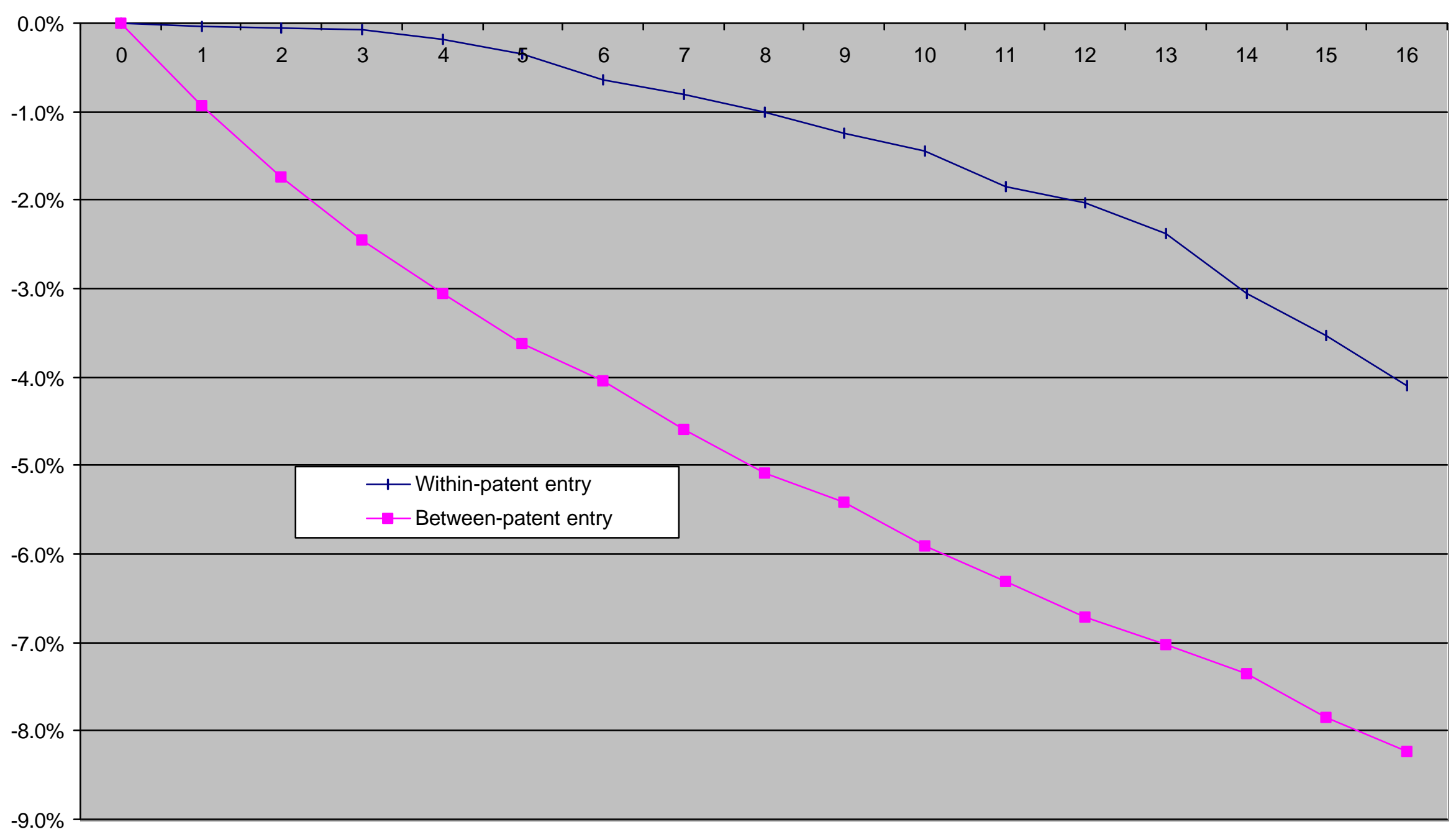

Age of drug (years) 
Figure 6

Estimated percentage reductions in PDV of innovator sales resulting from 1-year, 3-year, and 5-year acceleration of patent expiration

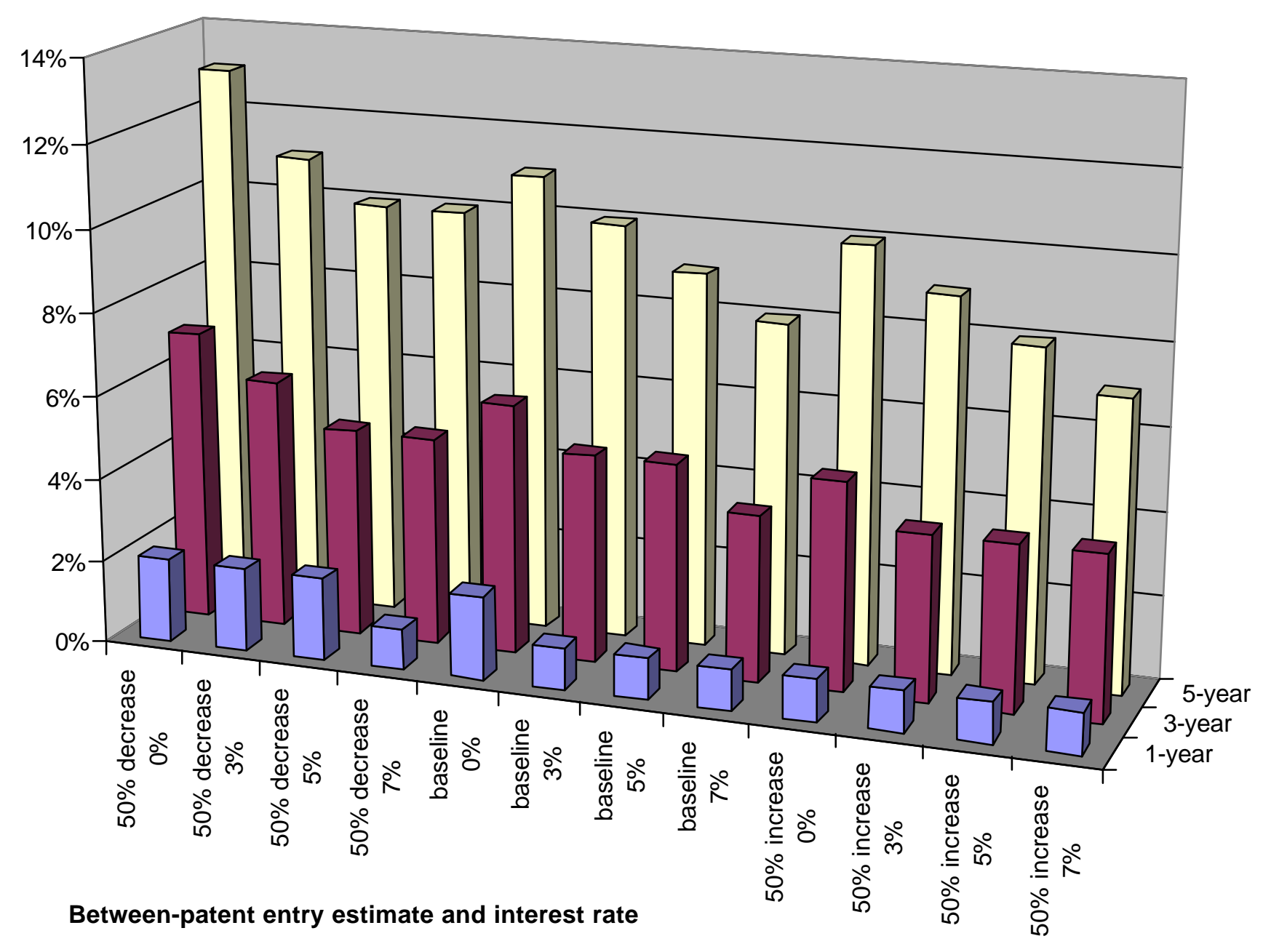




\section{Table 1}

Number of drugs approved in class, and number of applicants approved to market drug, by drug age, 1982-2001

\begin{tabular}{|c|c|c|}
\hline $\begin{array}{c}\text { Age of } \\
\text { drug } \\
\text { (years) }\end{array}$ & $\begin{array}{c}\text { No. of applicants approved } \\
\text { to market drug (log change } \\
\text { since FDA approval of drug) }\end{array}$ & $\begin{array}{c}\text { No. of drugs approved in class } \\
\text { (log change since FDA approval } \\
\text { of drug) }\end{array}$ \\
\hline 0 & $0.0 \%$ & $0.0 \%$ \\
\hline 1 & $0.4 \%$ & $4.9 \%$ \\
\hline 2 & $0.7 \%$ & $9.0 \%$ \\
\hline 3 & $1.2 \%$ & $12.6 \%$ \\
\hline 4 & $2.7 \%$ & $15.7 \%$ \\
\hline 5 & $5.3 \%$ & $18.7 \%$ \\
\hline 6 & $9.5 \%$ & $20.9 \%$ \\
\hline 7 & $11.9 \%$ & $23.7 \%$ \\
\hline 8 & $15.0 \%$ & $26.2 \%$ \\
\hline 9 & $18.5 \%$ & $28.0 \%$ \\
\hline 10 & $21.4 \%$ & $30.4 \%$ \\
\hline 11 & $27.4 \%$ & $32.5 \%$ \\
\hline 12 & $30.1 \%$ & $34.6 \%$ \\
\hline 13 & $35.1 \%$ & $36.2 \%$ \\
\hline 14 & $45.4 \%$ & $37.9 \%$ \\
\hline 15 & $52.3 \%$ & $40.4 \%$ \\
\hline 16 & $60.6 \%$ & $42.5 \%$ \\
\hline
\end{tabular}


Table 2

Summary Statistics from Medicaid State Drug Utilization Files

\begin{tabular}{|c|c|c|c|}
\hline Year & Total reimbursed amount & No. of Rx's & Average price of Medicaid Rx's \\
\hline 1996 & $\$ 9,681,165,484$ & $312,238,853$ & $\$ 31.01$ \\
\hline 1997 & $\$ 10,367,144,162$ & $305,764,591$ & $\$ 33.91$ \\
\hline 1998 & $\$ 12,418,148,656$ & $320,235,551$ & $\$ 38.78$ \\
\hline 1999 & $\$ 14,446,826,097$ & $328,031,366$ & $\$ 44.04$ \\
\hline
\end{tabular}


Table 3

Number and average price of Medicaid and non-Medicaid prescriptions in 1996

\begin{tabular}{|c|c|c|c|}
\hline & no. of 1996 Rx's & $\%$ of 1996 Rx's & average price \\
\hline Medicaid & $220,961,812$ & $10.2 \%$ & $\$ 33.02$ \\
\hline non-Medicaid & $1,944,887,113$ & $89.8 \%$ & $\$ 32.86$ \\
\hline Total & $2,165,848,925$ & $100.0 \%$ & $\$ 32.88$ \\
\hline
\end{tabular}

Medicaid Rx's refer to Rx's in which there was any payment by Medicaid.

The average price is the average amount paid by all payers. 
Table 4

Estimates of eq. (2)

(t-statistics in parentheses)

\begin{tabular}{|l|c|c|c|c|c|c|}
\hline \multicolumn{1}{|c|}{ Column } & 1 & 2 & 3 & 4 & 5 & 6 \\
\hline & \multicolumn{3}{|c|}{ Innovator drugs } & \multicolumn{3}{c|}{ Non-innovator drugs } \\
\hline & $\begin{array}{c}\text { no. of } \\
\text { units }\end{array}$ & $\begin{array}{c}\text { no. of } \\
\text { prescriptions }\end{array}$ & $\begin{array}{c}\text { dollar } \\
\text { value }\end{array}$ & $\begin{array}{c}\text { no. of } \\
\text { units }\end{array}$ & $\begin{array}{c}\text { no. of } \\
\text { prescriptions }\end{array}$ & dollar value \\
\hline Dependent variable: & & & & & & \\
\hline $\begin{array}{l}\text { Regressor: } \\
\text { patent competitors) }\end{array}$ & -0.194 & -0.190 & -0.175 & -0.104 & -0.080 & -0.077 \\
\hline & $(6.31)$ & $(7.80)$ & $(6.25)$ & $(5.44)$ & $(4.59)$ & $(5.10)$ \\
\hline $\begin{array}{l}\text { ln n (within-patent } \\
\text { competitors) }\end{array}$ & -0.068 & -0.077 & -0.081 & -0.240 & -0.256 & -0.248 \\
\hline & $(3.98)$ & $(5.71)$ & $(5.25)$ & $(13.46)$ & $(15.79)$ & $(17.59)$ \\
\hline
\end{tabular}

No. of products $\quad 31,980$

No. of observations 388,527

Quarterly data, 1996:2 - 1999:4 
Appendix Table 1

National Drug Code Directory Drug Classes

\begin{tabular}{|c|c|}
\hline Drug Class Code & Drug Class Name \\
\hline 0117 & ANESTHETICS, LOCAL \\
\hline 0118 & ANESTHETICS, GENERAL \\
\hline 0119 & ANESTHESIA, ADJUNCTS TO/ANALEPTICS \\
\hline 0120 & MEDICINAL GASES \\
\hline 0121 & ANESTHETICS, TOPICAL \\
\hline 0122 & ANESTHETICS, OPHTHALMIC \\
\hline 0123 & ANESTHETICS, RECTAL \\
\hline 0200 & ANTIDOTES \\
\hline 0281 & ANTIDOTES, SPECIFIC \\
\hline 0283 & ANTIDOTES, GENERAL \\
\hline 0285 & ANTITOXINS/ANTIVENINS \\
\hline 0286 & ANAPHYLAXIS TREATMENT KIT \\
\hline 0300 & ANTIMICROBIALS \\
\hline 0346 & PENICILLINS \\
\hline 0347 & CEPHALOSPORINS \\
\hline 0348 & LINCOSAMIDES/MACROLIDES \\
\hline 0349 & POLYMYXINS \\
\hline 0350 & TETRACYCLINES \\
\hline 0351 & CHLORAMPHENICOL/DERIVATIVES \\
\hline 0352 & AMINOGLYCOSIDES \\
\hline 0353 & SULFONAMIDES/RELATED COMPOUNDS \\
\hline 0354 & ANTISEPTICS,URINARY TRACT \\
\hline 0355 & ANTIBACTERIALS, MISCELLANEOUS \\
\hline 0356 & ANTIMYCOBACTERIALS (INCL ANTI LEPROSY) \\
\hline 0357 & QUINOLONES/DERIVATIVES \\
\hline 0358 & ANTIFUNGALS \\
\hline 0388 & ANTIVIRALS \\
\hline 0400 & HEMATOLOGICS \\
\hline 0408 & DEFICIENCY ANEMIAS \\
\hline 0409 & ANTICOAGULANTS/THROMBOLYTICS \\
\hline 0410 & BLOOD COMPONENTS/SUBSTITUTES \\
\hline 0411 & HEMOSTATICS \\
\hline 0500 & CARDIOVASCULAR-RENAL \\
\hline 0501 & CARDIAC GLYCOSIDES \\
\hline 0502 & ANTIARRHYTHMICS \\
\hline 0503 & ANTIANGINALS \\
\hline 0504 & VASCULAR DISORDERS, CEREBRAL/PERIPHERAL \\
\hline 0505 & HYPOTENSION/SHOCK \\
\hline 0506 & ANTIHYPERTENSIVES \\
\hline 0507 & DIURETICS \\
\hline 0508 & CORONARY VASODILATORS \\
\hline 0509 & RELAXANTS/STIMULANTS, URINARY TRACT \\
\hline 0510 & CALCIUM CHANNEL BLOCKERS \\
\hline 0511 & CARBONIC ANHYDRASE INHIBITORS \\
\hline 0512 & BETA BLOCKERS \\
\hline 0513 & ALPHA AGONISTS/ALPHA BLOCKERS \\
\hline
\end{tabular}




\begin{tabular}{|c|c|}
\hline 0514 & ACE INHIBITORS \\
\hline 0600 & CENTRAL NERVOUS SYSTEM \\
\hline 0626 & SEDATIVES/HYPNOTICS \\
\hline 0627 & ANTIANXIETY \\
\hline 0628 & ANTIPSYCHOTICS/ANTIMANICS \\
\hline 0630 & ANTIDEPRESSANTS \\
\hline 0631 & ANOREXIANTS/CNS STIMULANTS \\
\hline 0632 & CNS, MISCELLANEOUS \\
\hline 0633 & ALZHEIMER-TYPE DEMENTIA \\
\hline 0634 & SLEEP AID PRODUCTS (OTC) \\
\hline 0635 & ANTIEMETICS \\
\hline 0700 & CONTRAST MEDIA/ RADIOPHARMACEUTICALS \\
\hline 0789 & DIAGNOSTICS, RADIOPAQUE \& NONRADIOACTIVE \\
\hline 0790 & DIAGNOSTICS - RADIOPHARMACEUTICALS \\
\hline 0791 & THERAPEUTICS - RADIOPHARMACEUTICALS \\
\hline 0792 & DIAGNOSTICS, MISCELLANEOUS \\
\hline 0800 & GASTROINTESTINALS \\
\hline 0874 & DISORDERS, ACID/PEPTIC \\
\hline 0875 & ANTIDIARRHEALS \\
\hline 0876 & LAXATIVES \\
\hline 0877 & GASTROINTESTINAL, MISCELLANEOUS \\
\hline 0878 & ANTISPASMODICS/ANTICHOLINERGICS \\
\hline 0879 & ANTACIDS \\
\hline 0900 & METABOLICS/NUTRIENTS \\
\hline 0912 & HYPERLIPIDEMIA \\
\hline 0913 & VITAMINS/MINERALS \\
\hline 0914 & NUTRITION, ENTERAL/PARENTERAL \\
\hline 0915 & REPL/REGS OF ELECTROLYTES/WATER BALANCE \\
\hline 0916 & CALCIUM METABOLISM \\
\hline 0917 & HEMATOPOIETIC GROWTH FACTORS \\
\hline 1000 & HORMONES/HORMONAL MECHANISMS \\
\hline 1032 & ADRENAL CORTICOSTEROIDS \\
\hline 1033 & ANDROGENS/ANABOLIC STEROIDS \\
\hline 1034 & ESTROGENS/PROGESTINS \\
\hline 1035 & ANTERIOR PITUITARY/HYPOTHALMIC FUNCTION \\
\hline 1036 & BLOOD GLUCOSE REGULATORS \\
\hline 1037 & THYROID/ANTITHYROID \\
\hline 1038 & ANTIDIURETICS \\
\hline 1039 & RELAXANTS/STIMULANTS,UTERINE \\
\hline 1040 & CONTRACEPTIVES \\
\hline 1041 & INFERTILITY \\
\hline 1042 & DRUGS USED IN DISORDERS OF GROWTH HORMONE SECRETION \\
\hline 1100 & IMMUNOLOGICS \\
\hline 1180 & VACCINES/ANTISERA \\
\hline 1181 & IMMUNOMODULATORS \\
\hline 1182 & ALLERGENIC EXTRACTS \\
\hline 1183 & IMMUNE SERUMS \\
\hline 1200 & SKIN/MUCOUS MEMBRANES \\
\hline 1264 & ANTISEPTICS/DISINFECTANTS \\
\hline 1265 & DERMATOLOGICS \\
\hline
\end{tabular}




\begin{tabular}{|c|c|}
\hline 1266 & KERATOLYTICS \\
\hline 1267 & ANTIPERSPIRANTS \\
\hline 1268 & TOPICAL STEROIDS \\
\hline 1269 & BURN/SUNBURN, SUNSCREEN/SUNTAN PRODUCTS \\
\hline 1270 & ACNE PRODUCTS \\
\hline 1271 & TOPICAL ANTI-INFECTIVES \\
\hline 1272 & ANORECTAL PRODUCTS \\
\hline 1273 & PERSONAL CARE PRODUCTS (VAGINAL) \\
\hline 1274 & DERMATITIS/ANTIPURETICS \\
\hline 1275 & TOPICAL ANALGESICS \\
\hline 1300 & NEUROLOGICS \\
\hline 1371 & EXTRAPYRAMIDAL MOVEMENT DISORDERS \\
\hline 1372 & MYASTHENIA GRAVIS \\
\hline 1373 & SKELETAL MUSCLE HYPERACTIVITY \\
\hline 1374 & ANTICONVULSANTS \\
\hline 1400 & ONCOLYTICS \\
\hline 1479 & ANTINEOPLASTICS \\
\hline 1480 & HORMONAL/BIOLOGICAL RESPONSE MODIFIERS \\
\hline 1481 & ANTIMETABOLITES \\
\hline 1482 & ANTIBIOTICS, ALKALOIDS, AND ENZYMES \\
\hline 1483 & DNA DAMAGING DRUGS \\
\hline 1500 & OPHTHALMICS \\
\hline 1566 & GLAUCOMA \\
\hline 1567 & CYCLOPLEGICS/MYDRIATICS \\
\hline 1568 & OCULAR ANTI-INFECTIVE/ANTI-INFLAMMATORY \\
\hline 1569 & OPHTHALMICS, MISCELLANEOUS \\
\hline 1570 & OPHTHALMICS-DECONGESTANTS/ANTIALLERGY AGENTS \\
\hline 1571 & CONTACT LENS PRODUCTS \\
\hline 1600 & OTICS \\
\hline 1670 & OTICS, TOPICAL \\
\hline 1671 & VERTIGO/MOTION SICKNESS/VOMITING \\
\hline 1700 & RELIEF OF PAIN \\
\hline 1720 & ANALGESICS, GENERAL \\
\hline 1721 & ANALGESICS-NARCOTIC \\
\hline 1722 & ANALGESICS-NON-NARCOTIC \\
\hline 1723 & ANTIMIGRAINE/OTHER HEADACHES \\
\hline 1724 & ANTIARTHRITICS \\
\hline 1725 & ANTIGOUT \\
\hline 1726 & CENTRAL PAIN SYNDROMES \\
\hline 1727 & NSAID \\
\hline 1728 & ANTIPYRETICS \\
\hline 1729 & MENSTRUAL PRODUCTS \\
\hline 1800 & ANTIPARASITICS \\
\hline 1860 & ANTIPROTOZOALS \\
\hline 1862 & ANTHELMINTICS \\
\hline 1863 & SCABICIDES/PEDICULICIDES \\
\hline 1864 & ANTIMALARIALS \\
\hline 1900 & RESPIRATORY TRACT \\
\hline 1940 & ANTIASTHMATICS/BRONCODILATORS \\
\hline 1941 & NASAL DECONGESTANTS \\
\hline
\end{tabular}




\begin{tabular}{|l|l|}
\hline 1943 & ANTITUSSIVES/EXPECTORANTS/MUCOLYTICS \\
\hline 1944 & ANTIHISTAMINES \\
\hline 1945 & COLD REMEDIES \\
\hline 1946 & LOZENGE PRODUCTS \\
\hline 1947 & CORTICOSTEROIDS-INHALATION/NASAL \\
\hline 2000 & UNCLASSIFIED/MISCELLANEOUS \\
\hline 2087 & UNCLASSIFIED \\
\hline 2095 & PHARMACEUTICAL AIDS \\
\hline 2096 & SURGICAL AIDS \\
\hline 2097 & DENTAL PREPARATIONS \\
\hline 2098 & DENTRIFICE/DENTURE PRODUCTS \\
\hline 2099 & MOUTH PAIN, COLD SORE, CANKER SORE PRODUCTS \\
\hline 2100 & HOMEOPATHIC PRODUCTS \\
\hline
\end{tabular}

